\title{
A SAÚDE E OS PROCESSOS DE TRABALHO NO CAPITALISMO: REFLEXÕES NA INTERFACE DA PSICODINÂMICA DO TRABALHO E DA SOCIOLOGIA DO TRABALHO
}

\author{
Álvaro Roberto Crespo Merlo \\ Naira Lima Lapis \\ Universidade Federal do Rio Grande do Sul, Porto Alegre, Brasil
}

\begin{abstract}
RESUMO: A organização dos processos de trabalho nos quais estão inseridos os trabalhadores produz graves consequiências sobre a saúde. Essas têm origem, principalmente, na separação entre concepção e execução, introduzidas pelos modelos de gestão taylorista e fordista. As mudanças promovidas pela implementação do modelo de gestão japonês passaram a demandar um trabalhador aparentemente mais engajado ao seu trabalho, apto a realizar diversas operações e mais escolarizado. Porém, observa-se que ao sofrimento daqueles que trabalham em tarefas que não foram atingidas pela reestruturação produtiva, acrescenta-se o sofrimento provocado pelas transformações em curso no trabalho, exigindo novos atributos ao trabalhador, atingindo a saúde física e mental.
\end{abstract}

PALAVRAS-CHAVE: Processos de trabalhos; sofrimento psíquico no trabalho; saúde mental.

\section{HEALTH AND LABOR PROCESSES IN CAPITALISM: CONSIDERATIONS ON THE INTERFACE BETWEEN THE PSYCHODYNAMICS AND SOCIOLOGY OF WORK}

ABSTRACT: Workers are submitted to labor processes that produce serious health consequences. Mainly, these consequences originate from management models that separate conception from execution, introduced by Taylorism and Fordism. The implementation of the Japanese management model incurred changes that demanded a more educated worker capable of accomplishing several tasks, and who is apparently more committed to his/her work. However, the physical and mental health of workers whose activities were not affected by production restructuring is being affected by the transformations presently in course in the workplace, such as new performances and demands.

KEYWORDS: labor processes, psychic suffering in the workplace, mental health.

\section{Considerações Iniciais}

A percepção de que o trabalho tem conseqüências sobre a saúde dos indivíduos é antiga. Pode-se encontrála no clássico Tempos Modernos, de Charlie Chaplin sensível às degradações física e mental provocadas pela implementação do modelo taylorista/fordista sobre os trabalhadores -, e nas pesquisas da Sociologia do Trabalho de Friedmann e Naville (1962), que relataram as consequiências do trabalho na linha de montagem, na França dos anos 50 do século passado, ou ainda, mais remotamente, nos estudos de Ramazzinni, considerado o fundador da Medicina do Trabalho no século XVIII.

O processo da gênese e da consolidação do capitalismo compreendeu diversos ciclos de crescimento e de crises. As suas diferentes fases de desenvolvimento foram marcadas por importantes mudanças em termos de inovações tecnológicas, qualificação do trabalhador, modos de organização do trabalho e da produção, estratégias empresariais, formas de controle sobre os trabalhadores, desempenho dos sindicatos e papel do Estado. Esse conjunto de transformações, características de determinadas etapas históricas do capitalismo, costuma ser chamado de Revolução Industrial.

A Primeira Revolução Industrial ocorreu em meados do século XVIII, na Inglaterra, quando se iniciou o uso intensivo de mão-de-obra assalariada. Ela é freqüentemente associada ao trabalho pesado e insalubre na indústria têxtil, tendo como referência tecnológica fundamental o uso da máquina a vapor. Dois aspectos importantes dessa fase do capitalismo cabem serem referidos: a qualificação do trabalhador e as suas estratégias de resistência.

Modificações substanciais aconteceram na sua qualificação. O trabalhador, que, até então, detinha um significativo conhecimento sobre o conteúdo do seu trabalho, passou, gradualmente, a ter expropriado seu saber-fazer, ao mesmo tempo em que se aprofundou a divisão do trabalho. Não se pode, contudo, afirmar que houve uma desqualificação generalizada do trabalhador. Ferreira (2002, p. 69) ressalta, que “....a evolução da Primeira Revolução Industrial se teria tornado difícil sem o perfil profissional e as qualificações do operariado."

No que tange às estratégias de resistência dos trabalhadores, entrelaçaram-se diferentes formas para dificultar o desenvolvimento da produção, que vão desde a sabotagem, como danificação das máquinas, atrasos e absenteísmo, até a ocorrência de greves. Essa resistência operária se alicerçava, dentre outros, em dois importantes pilares: por um lado, o relativo desconhecimento do empregador quanto ao conteúdo do trabalho, o qual era transmitido oralmente de geração em geração, sendo que os métodos e as técni- 
cas de trabalho não eram registrados ou documentados; por outro, a complexidade da maquinaria era ainda incipiente. Nesse contexto, foi possível aos trabalhadores exercerem um relativo controle sobre o processo de trabalho no que concerne às pausas, aos movimentos e aos tempos de realização das operações.

Nessa primeira etapa do capitalismo, o controle exercido sobre os trabalhadores expressava-se sob a forma mais autoritária possível. O despotismo fabril materializava-se em agressões físicas, ameaças, castigos, multas e demissões. Tal fase caracterizou-se pela intensificação do trabalho, por longas jornadas - de 12 a 15 horas diárias -, por condições de trabalho precárias e por salários aviltantes. O movimento sindical estruturava-se de forma ainda débil, e era tímida a função do Estado enquanto regulador das relações entre o capital e o trabalho.

Nesse cenário, onde os trabalhadores não dispunham de um efetivo sistema de proteção social, sucediam-se inúmeros e graves acidentes de trabalho, como perda de dedos, esmagamento de mãos, queimaduras, lesões causadas pelas ferramentas que caíam sobre os mesmos. Diferentes tipos de doenças profissionais acometiam os trabalhadores e, muito freqüentemente, levavam à morte de crianças, mulheres e homens: doenças pulmonares, cutâneas, cardíacas, respiratórias e estresse físico e mental.

Marx retrata, em sua obra $O$ Capital, a desproteção à qual estavam submetidos os trabalhadores, notadamente as mulheres e as crianças, no período de apogeu da indústria têxtil, na Inglaterra. No que diz respeito ao trabalho infantil, esse autor (1968, p. 482) descreve os riscos aos quais as crianças estavam expostas: "As máquinas de fiar automáticas são talvez as mais perigosas. A maioria dos acidentes atinge crianças que se arrastam embaixo das máquinas para varrer o chão, enquanto elas estão em movimento."

Quanto ao trabalho das mulheres, Marx (1968), citando o relatório do Inspetor de Fábrica Saunders, de 1844, também referente à indústria têxtil na Inglaterra, revela a brutal sujeição à qual elas estavam entregues, destacando, dentre outros fatores, a extensão da jornada de trabalho:

Entre as mulheres operárias, há mulheres que trabalham muitas semanas seguidas, com exceção de alguns dias, de 6 da manhã até meia-noite, com menos de 2 horas para refeições, de modo que, em 5 dias na semana, só dispõem de 6 horas das 24, a fim de ir para casa, dormir e voltar (Saunders, apud Marx, 1968, p. 460).

\section{Os processos de trabalho Taylorista e Fordista e o adoecimento do trabalhador}

2.1 O modelo Taylorista de organização do trabalho A Segunda Revolução Industrial, no final do século XIX e início do século XX, nos EUA, período em que a eletricidade passou gradativamente a fazer parte do cotidiano das cidades e a alimentar os motores das fábricas, caracterizou-se pela administração científica do trabalho e pela produção em série. Foi a época da difusão do modelo taylorista/fordista de organização do trabalho, da rígida especialização das tarefas e da racionalização da produção.

O taylorismo, ou a administração científica do trabalho, surgiu, nesse período, como uma nova cultura do trabalho, quando o conhecimento científico se tornou relevante, sobretudo para o desenvolvimento das indústrias química, elétrica e metalúrgica, correspondendo às necessidades de uma etapa do capitalismo internacional, período de atuação monopolista do capital.

Em seus estudos, Taylor (1995) observou que boa parte dos problemas de baixa produtividade das fábricas se deviam à enorme variação de tempo e de rendimento no trabalho individual dos operários. Coexistiam, numa mesma empresa, diversas maneiras de executar uma idêntica atividade, e os métodos de produção eram, em geral, transmitidos oralmente de trabalhador a trabalhador ou aprendidos por intermédio da observação. Prêmios, ameaças e sanções não obtinham os resultados esperados.

Taylor (1995) sabia que os empregadores desconheciam parte significativa dos conteúdos do trabalho e do tempo necessário para a execução de cada atividade e que, enquanto isso ocorresse, ou seja, enquanto os operários detivessem o conhecimento de uma parte importante do processo de trabalho, não seria possível diminuir os tempos ociosos e o "fazer cera", tão desastrosos do ponto de vista da produtividade. A questão implicava buscar métodos objetivos de execução, os quais, além de serem uniformes, deveriam ser determinados de forma externa, prescritos pela gerência. Segundo a lógica taylorista, as atividades não mais poderiam ser realizadas ao bel-prazer dos trabalhadores.

A administração científica de Taylor (1995) visava racionalizar a organização do trabalho, o que envolveu buscar normas, procedimentos sistemáticos e uniformes. Pela observação, pela descrição e pela medição, seria possível simplificar as operações, eliminar os movimentos desnecessários, lentos e ineficientes e encontrar "o modo melhor", o movimento certo e mais rápido em todos os ofícios. Embora a cronometragem já houvesse sido utilizada para coordenar e acelerar o trabalho, com Taylor, o estudo do tempo, associado ao estudo dos movimentos, levou à busca do único e melhor método de execução como norma a ser seguida permanentemente pela empresa.

Esses métodos e técnicas de trabalho não eram elaborados pelos trabalhadores - embora fosse das sugestões deles que deveriam partir as melhores idéias para aprimorar o processo produtivo -, visto que a preparação do trabalho passou a ser atribuição de especialistas, como engenheiros. Estava consolidando-se, no capitalismo, uma 
radical separação entre o saber e o fazer; entre a concepção, o planejamento e a execução; entre o trabalho manual dos operários e o trabalho intelectual das gerências.

Com o estudo dos tempos e movimentos, o trabalho foi decomposto em parcelas cada vez mais elementares e simplificadas. Cada tarefa passou a corresponder a um posto de trabalho, o qual deveria ser ocupado não por qualquer trabalhador, mas pelo homem certo. Isso significa que Taylor percebeu a importância de se aprimorarem as formas de recrutamento. Estas passaram a ter como objetivo principal selecionar de maneira criteriosa o trabalhador mais adequado para cada tarefa, para cada posto de trabalho, o que ficou conhecido como "o homem certo no lugar certo."

\section{Segundo Heloani (2002, p. 30):}

A formulação 'científica' das práticas de seleção $e$ treinamento reflete a consolidação do padrão tecnológico da Segunda Revolução Industrial. Esse padrão passa a exigir formas de administração mais sofisticadas, que aprofundam as exigências de adestramento. Como conseqüência, a seleção deve ser individualizada, e a antiga forma de recrutamento 'em massa' deve ser abandonada nos principais ramos (industriais de ponta).

Além do estudo das tarefas, da seleção do trabalhador mais adequado para a sua execução e do treinamento, configuram-se, entre os objetivos tayloristas de racionalização do trabalho, os incentivos salariais com vistas à elevação da produtividade.

Estímulos ao desempenho individual, como salários e prêmios por produção, associados ao estudo de tempos e movimentos, tiveram como fundamento, na óptica taylorista, modelar a subjetividade do trabalhador, o qual “....assimila o 'desejo' de aumentar a produção e passa a reorientar a sua percepção para este aumento" (Heloani, 2002, p. 31). Acrescenta-se que o taylorismo se associa, ainda, à criação de uma estrutura organizacional rígida, hierarquizada, com especialistas de controle, normas burocráticas e vigilância permanente dos supervisores.

Essas considerações permitem perceber a estreita relação entre a administração científica taylorista e a apropriação do conhecimento do trabalhador. O trabalho é transformado em atividade parcelada, repetitiva e sem sentido, retirando do indivíduo a sua capacidade criativa.

Taylor de fato exprime, com cinismo brutal, o fim da sociedade americana; desenvolver no trabalhador, no máximo grau, atitudes maquinais e automáticas, despedaçar o velho nexo psicofísico do trabalho profissional qualificado, que exigia uma certa participação ativa da inteligência, da fantasia, da iniciativa do trabalhador e reduzir as operações produtivas ao seu único aspecto físico maquinal (Gramsci, 1978, p. 328).
No modelo taylorista, a principal fonte de agressão à saúde do trabalhador é a própria organização do trabalho. Na medida em que a concepção passa a ser monopólio da gerência científica, é necessário que as tarefas a serem realizadas pelos trabalhadores sejam predefinidas nos seus mínimos detalhes. Trata-se da essência mesmo dos princípios indicados por Taylor (1995), descrever minuciosamente cada tarefa a ser executada, para garantir a máxima produtividade. Aqui, é oportuno distinguir tarefa de atividade. A primeira corresponde ao que deve ser feito segundo definições precisas; a segunda, ao que é efetivamente realizado. Entre tarefa e atividade haverá, portanto, um necessário ajuste, que conduzirá a uma redefinição dos objetivos inicialmente fixados. Esse reajuste constitui uma parte enigmática do trabalho, e sua resolução fica necessariamente ao encargo do trabalhador, para que a produção possa fluir conforme as quantidades calculadas, com a qualidade prevista e com condições mínimas de segurança para os indivíduos e para as instalações (Merlo, 1998). A principal crítica dirigida ao taylorismo é a de que ele impede a conquista da identidade no trabalho, a qual ocorre, precisamente, no espaço entre trabalho prescrito e trabalho real. A organização científica do trabalho não se limita apenas à desapropriação do saber; ela inibe também qualquer iniciativa de organização e de adaptação ao trabalho, pois tal adaptação exige uma atividade intelectual e cognitiva não almejada pelo taylorismo (Dejours, 1993), apesar de, na prática, ela não desaparecer totalmente. No entanto, na prática, isto não ocorre, pois o trabalho real implica algum grau de aleatoriedade e imprevisão, o que deve ser, obrigatoriamente, resolvido pela inteligência e pela experiência do trabalhador (Daniellou, Laville \& Teiger, 1989). Essa possibilidade de intervir de alguma maneira para preencher as lacunas não previstas pelas determinações da gerência e o reconhecimento, pelo próprio trabalhador, desse tipo de contribuição individual à manutenção da qualidade e da produtividade são essenciais para a conservação de sua saúde mental e vão de encontro ao prescrito no modelo taylorista.

As "marcas" do trabalho (Teiger, 1980), que aparecem sob a forma de modificações de conduta no ambiente fora do trabalho, de sofrimento psíquico ou mesmo de doenças físicas e psíquicas, têm, como uma de suas fontes, a rigidez do taylorismo, no qual a distância entre o trabalho prescrito e o trabalho real é quase inexistente e onde não está prevista a iniciativa por parte do trabalhador.

A fragmentação da tarefa, tal qual instaurada pelo taylorismo, exige respostas fortemente personalizadas, que direcionam, prioritariamente, para dois sofrimentos provocados pelo trabalho: o medo e a monotonia.

No que concerne à monotonia, a intensificação do ritmo de trabalho, a extrema parcelização das tarefas, a rotina burocrática, o permanente controle, os movimentos 
repetitivos, determinados pela esteira rolante, tornam o trabalho um pesado fardo. Quanto ao medo vivenciado pelo trabalhador (Dejours, 1993), aponta distintas dimensões. Aquele relacionado ao desgaste do funcionamento mental e do equilíbrio psicoafetivo, o qual pode originarse na desestruturação das relações entre os colegas, manifestando-se por meio da discriminação, da suspeição ou, ainda, de relações de violência e de agressividade, opondo trabalhadores entre si e com a hierarquia. Existe também o medo específico relativo à desorganização do funcionamento mental, devido à auto-repressão exercida sobre o aparelho psíquico e pelo esforço empregado para se manterem comportamentos condicionados. Há, ainda, o medo referente à deterioração do corpo físico, vinculado diretamente às más condições de trabalho.

Sem negar a importância dos cerceamentos psíquicos ligados ao trabalho na geração do sofrimento, Dejours (1993) chama atenção para o fato de que é principalmente a falta de possibilidades para se mudarem, ou mesmo aliviarem, esses cerceamentos a origem dos problemas de saúde.

\subsection{Apontamentos a Respeito do Modelo Fordista de Organização do Trabalho}

A partir de 1910, a organização científica do trabalho expandiu-se, e a difusão e a consolidação do taylorismo deram-se pela sua associação com os princípios, com os métodos e com a tecnologia utilizados pelo também norteamericano Henry Ford. ${ }^{1} \mathrm{Se}$, com Taylor (1995), já havia um controle dos tempos de trabalho de cada operário, a conexão entre as diferentes tarefas ainda não tinha sido efetivada. Ford criou, então, a esteira rolante, cujas peças desfilavam diante dos trabalhadores colocados, lado a lado, na linha de montagem, unindo tarefas individuais sucessivas, fixando uma cadência regular de trabalho e reduzindo o transporte entre as operações.

Com o fordismo, a divisão do trabalho e a parcelização das tarefas foram intensificadas. A busca da diminuição dos tempos ociosos estendeu-se à integração entre os postos de trabalho, à medida que o tempo de transferência das peças passou a ser dado não exclusivamente pelas ordens hierárquicas, mas principalmente por meio de dispositivos mecânicos, encadeando as tarefas continuamente. É como se as ordens das chefias e o controle direto aperfeiçoados por Taylor (1995), com a imposição de tempos e de movimentos de execução, fossem incorporados às instalações. Os trabalhadores ficaram mais submetidos ao ritmo automático, à cadência das máquinas, à rotina, executando, várias vezes, um mesmo movimento em uma linha de montagem.

Com a fragmentação das operações distribuídas por diversos postos de trabalho, com a linha de montagem acoplada à esteira rolante, o que evitava o deslocamento dos trabalhadores e garantia um fluxo contínuo das peças e de partes destas, em 1914, nas usinas Ford, de Detroit, houve uma expressiva diminuição no tempo de produção, aumento da quantidade produzida e redução no preço do famoso Modelo Ford T. Isso representou muito mais do que meras inovações restritas ao universo fabril.

O fordismo consolidou um novo modelo de desenvolvimento, caracterizado pela produção em massa e pelo consumo de massa, o que colocava as necessidades de ampliar mercados e de estabelecer um novo patamar de rendimentos para aos trabalhadores. Como forma de estimular a produção, Ford propôs a jornada de oito horas a US\$ 5, quase o dobro do salário médio de então. Segundo Harvey (1992, p. 121), no entanto, especial e inovador em Ford foi:

\begin{abstract}
...seu reconhecimento explícito de que a produção de massa significava consumo de massa, um novo sistema de reprodução da força de trabalho, uma nova política de controle e gerência do trabalho, uma nova estética e uma nova psicologia, em suma, um novo tipo de sociedade democrática, racionalizada, modernista e populista.
\end{abstract}

Em sua análise sobre a expansão do fordismo nos EUA, Gramsci (1978) salienta que novos métodos de trabalho são inseparáveis de um novo modo de viver. Assim, questões relacionadas à sexualidade, à moralidade e ao consumismo estavam vinculadas ao surgimento de um novo tipo de trabalhador, de um novo padrão de produção e de consumo, enfim, de um novo tipo de sociedade. Esse autor destaca que aquele que não tinha uma vida regrada era visto, por Ford, como um mau trabalhador, da mesma forma que a exaltação passional, na visão fordista, não estaria de acordo com os movimentos cronometrados do mais perfeito automatismo.

Beyon, ao descrever a fábrica de automóveis de River Rouge, de Ford, nos anos 30 e 40 do século XX, cita o livro de Keith Sward, onde é retratado o sofrimento físico e psíquico ao qual estavam entregues os trabalhadores, submetidos a intenso ritmo de trablaho, severa disciplina e rígido controle no interior e fora da fábrica:

Conversar ou confraternizar com colegas de trabalho na hora do almoço era tabu nos velhos tempos, época que durou vinte anos ou mais. Era então normal, durante o intervalo do meio dia, ver um empregado da Ford agachado no chão, carrancudo e reservado, mastigando sua comida no mais completo isolamento (Sward apud Beyon, 1995, p. 54).

No que concerne à proibição de falar, cantarolar, assobiar e sorrir no trabalho, medida adotada para não atrasar a linha de produção, os trabalhadores desenvolveram diferentes habilidades - para driblar os vigilantes e se comunicar entre eles - que ficaram conhecidas como a "fordização da face":

Um mecânico muito inteligente nesse departamento (ferramenteiros e estampadores) inventou um tipo 
todo próprio de 'linguagem da Ford': aprendeu a falar com o ventríloquo. Depois de passar dez anos trabalhando na Ford, esse homem transformou-se em objeto de ridículo para a esposa e os amigos, pois o hábito de falar pelo lado da boca sem mover os lábios acabou por torna-se ingovernável; ele passou a falar dessa maneira inconscientemente, em casa ou em conversas informais com pessoas fora do ambiente de trabalho (Sward apud Beynon, 1995, p.54).

O modelo fordista está estreitamente associado tanto ao modo norte-americano de trabalhar e viver, aos aumentos salariais para estimular o consumo e, de certa forma, convencer o trabalhador a submeter-se ao ritmo acelerado de trabalho, deixando o prazer para a vida no póstrabalho, quanto a um novo tipo de Estado.

A produção em série atingia seu ápice ligada, inevitavelmente, ao triunfo da sociedade de consumo e à melhoria do nível de vida norte-americano de 1920 a 1929. O modelo fordista foi recebido, no mundo, como o american way of life no final da Segunda Guerra Mundial, fundado no hedonismo - na busca da felicidade por meio do aumento do consumo como uma meta a ser alcançada.

No que diz respeito à difusão do fordismo - preservadas as especificidades de cada país, como a sua história, os sistemas político, social, cultural e o nível de desenvolvimento econômico - sua propagação diversificada expandiu-se pela Europa Ocidental. No pós Segunda Guerra Mundial, consolidou-se o intervencionismo estatal, apoiado nas políticas keynesianas, especialmente nos países europeus, sob a égide da social-democracia.

O Estado de Bem-Estar Social assumiu, então, um conjunto de atribuições. A produção em massa necessitava, para ser lucrativa, de uma demanda estável, com políticas dirigidas a investimentos públicos vitais para o crescimento da produção e do consumo e para garantir o pleno emprego. Além disso, buscava-se fornecer um forte complemento ao salário do trabalhador/consumidor, com um amplo programa de políticas públicas, como educação, saúde, habitação, seguro-desemprego, seguridade social. Afinal, o sistema de previdência social permitia aos assalariados continuarem como consumidores mesmo quando desempregados, doentes ou aposentados.

As políticas de proteção social do Welfare State serviam em muito para acalmar o movimento dos trabalhadores, intensificado, por uma lado, pela quebra de autonomia e iniciativa, própria do modelo taylorista/fordista, e, por outro, desde a Revolução Russa, fortemente influenciado pelas idéias socialistas.

Com o Plano Marshall pela recuperação da Europa Ocidental, com aporte do capital norte-americano, no pós Segunda Guerra Mundial, o fordismo tornou-se referência para o setor industrial, principalmente no ramo automobi- lístico. Quanto aos concorrentes nesse ramo da economia, ou se adaptavam, ou desapareciam, e o modelo estendeuse a ponto de condicionar a maioria das empresas a implementá-lo. Salienta-se, contudo, que, quando sua aplicação se generalizou, a competição se acirrou, e os recursos destinados a certas melhorias nas condições de trabalho passaram a ser reduzidos. A busca por diminuição nos custos de produção levou vários países da Europa Ocidental dos anos 60, por exemplo, a introduzir trabalhadores imigrantes, para pressionar os salários, deteriorando as condições de trabalho (Gounet, 1999).

O modelo taylorista/fordista, com suas particularidades, prevaleceu como modo de organizar o trabalho e a produção nos países capitalistas desenvolvidos até meados dos anos 70. Nessa época, a "era de ouro" do capitalismo, com crescimento econômico e relativa redistribuição de renda, estava chegando ao fim. O modelo de produção em massa exigia crescimento estável em mercados de consumo constantes.

Os países capitalistas avançados vivenciaram então um período de crise, que se manifestou em diferentes instâncias. O movimento estudantil passou a criticar os valores e o modo de vida prevalecentes no sistema capitalista. Acirraram-se as lutas dos trabalhadores diante do trabalho parcelado, repetitivo, especializado, com rígida disciplina e severo controle. A esse contexto agregaram-se os choques do petróleo, o término da convertibilidade do dólar em ouro e a flutuação das moedas. As consequiências expressaram-se na inflação ascendente e na diminuição dos investimentos na produção. Lipietz (1991) denominou essa crise como de lucratividade. Começou a desfazer-se o compromisso fordista entre Estado, empregador e trabalhador.

\section{Notas sobre o Toyotismo e sua relação com a saúde do trabalhador}

A Terceira Revolução Tecnológica em curso, iniciada nos anos 70 do século passado, tem como modelo de organização do trabalho a experiência japonesa conhecida por toyotismo. Foi agilizada pelos avanços da microeletrônica e vem apresentando formas de organizar o trabalho distintas do modelo anterior, fundadas na diversificação de operações e no envolvimento do trabalhador com os objetivos da empresa.

Essa nova fase do capitalismo foi marcada por mudanças profundas. Difundiu-se uma nova base técnica, a microeletrônica - desenvolvendo a informática, a automação, a robótica e a telemática -; os mercados e a produção internacionalizaram-se, comprometendo a regulação fordista.

Para enfrentar a crise, reformularam-se as estratégias empresariais. As empresas passaram a buscar a superação da rigidez do modelo fordista, a procurar novas linhas de produtos e novos nichos de mercado, a dispersar geogra- 
ficamente a produção para regiões onde as organizações sindicais fossem menos organizadas e os salários mais baixos, a recorrer às fusões e a medidas para acelerar o tempo de giro do capital.

Passaram, assim, a ser adotadas novas formas de organização do trabalho e da produção, inspiradas no modelo japonês. Os diferenciais trazidos pelos métodos japoneses devem-se, em boa parte, às adaptações à produção fordista no pós Segunda Guerra Mundial. À época, no Japão, a demanda mostrava-se reduzida, diversificada e dirigida, no caso dos automóveis, a veículos menores, quando comparados aos norte-americanos. Assim, foi preciso adequar a produção em série ao padrão de consumo do país. $\mathrm{O}$ crescimento da indústria automobilística do Japão foi também impulsionado pelo governo, na medida em que foram erguidas barreiras alfandegárias, concedidos empréstimos subsidiados, encorajada a concentração das empresas, racionalizado o ramo de autopeças e desenvolvida a malha rodoviária. Nasceu, desse modo, o modelo japonês de gestão conhecido como toyotismo, ${ }^{2}$ já que a Toyota foi a primeira empresa a implementá-lo.

Tendo como objetivos elevar a produtividade, reduzir custos e promover um controle preciso da qualidade, o toyotismo apresentou ao Ocidente técnicas, métodos e princípios de relações humanas e de participação no interior da empresa diferentes dos utilizados até então. Destacam-se o Just-in-Time, o Kanban, o Kayzen, os sistemas de sugestões, os círculos de controle de qualidade e os programas de Total Quality Control, este envolvendo fornecedores e subcontratados na luta pela qualidade.

Dessa forma, a partir dos anos 70, o toyotismo começou a difundir-se pelos diferentes países, e seus conceitos, integrados ou isoladamente, passaram a ser aplicados, significando uma alternativa para solucionar os problemas enfrentados pelo capitalismo ocidental. Pautado na utilização de métodos capazes de manter sua eficiência sob condições de demanda restrita e com oscilações constantes no mercado, no chamado modelo japonês de gestão, a concorrência alicerçou-se na criação de novas necessidades, no aprimoramento da qualidade, na diversificação e na personalização da oferta.

Mas o que interessa refletir aqui são as demandas desse novo modelo - com seus diferentes matizes ${ }^{3}$ - sobre o trabalhador: um trabalhador mais escolarizado, com raciocínio lógico, com capacidades de se relacionar com os colegas e de operar equipamentos diversificados e complexos, apto a realizar diversas operações, motivado para o trabalho, engajado com os objetivos da empresa, um colaborador. Será que, enfim, o autômato taylorista seria substituído por um trabalhador participativo e envolvido com seu trabalho? Será que essa nova maneira de preocupar-se com os recursos humanos significa repudiar o esgotamento físico e psicológico do trabalhador que tem seus movimentos controlados pelo cronômetro e suas tarefas segmentadas?

Segundo Malaguti (1996), esse novo trabalhador e as "virtuosas" relações de trabalho japonesas não servem de contraponto ao modelo taylorista/fordista. Basear a crítica a esse modelo nesse pretenso virtuosismo é uma ilusão, pois o que realmente muda é que, agora, cada trabalhador deve concentrar-se não mais em uma única tarefa, mas num conjunto de operações diferentes e encadeadas nãolinearmente:

...os movimentos e os gêneros de raciocínio próprios a todas, e a cada uma delas, devem estar sempre presentes nas memórias corporal e intelectual do trabalhador. Ao mesmo tempo, é aumentado o número, e diminuída a extensão temporal, dos intervalos de adaptação intertarefas, provocando uma mais numerosa sucessão de esforços antiinerciais. Em outras palavras, durante toda a jornada de trabalho, o trabalhador vê aumentada sua tensão nervosa, muscular e intelectual. Em resumo, o método kanban elevou a intensidade do trabalho a níveis somente observados na época áurea do taylorismo... (Malaguti, 1996, p. 59).

Nas células de produção, características do toyotismo, a polivalência e a rotatividade de operações são formas de garantir a continuidade e o ritmo da produção diante das ausências, das pausas e das dificuldades, ocorrendo uma certa complementaridade do trabalho, em que atividades de manutenção e de qualidade passam a ser incorporadas ao dia-a-dia. As rígidas formas de controle, típicas do modelo taylorista/fordista, aparecem transformadas em lideranças motivadoras, num ambiente em que o próprio grupo exerce pressão sobre os indivíduos.

...parte da disciplina externa na forma de despotismo direto é substituída por uma disciplina que emana do despotismo coletivo. Ou seja, quanto mais fortes são as formas indiretas de controle sobre a força de trabalho, menores tendem a ser as formas diretas de controle (Cipolla, 2003, p. 88-89).

Malaguti (1996) salienta que o exercício direto do controle tende, assim, a se atenuar, pois os grupos de trabalho criam reações psíquicas de autocontrole nos seus integrantes, tais como: a introjeção dos valores da empresa, o estímulo ao orgulho profissional, o controle "corpo a corpo" e a emulação psicológica, a qual visa, antes de tudo, esconder a oposição de interesses entre trabalhadores e gerência, num clima de pseudoliberdade.

Ao mesmo tempo em que se flexibilizam as empresas, o trabalho, os trabalhadores, a produção, os produtos, os mercados e os padrões de consumo, cresce o desemprego - advindo, em boa parte, da introdução de inovações tecnológicas poupadoras de mão-de-obra -, e disseminam-se formas precárias de relações de trabalho, como os contra- 
tos por tempo parcial, os contratos temporários e a subcontratação. Sennett (2001), refletindo sobre as características do "novo capitalismo" e detendo-se na intensa flexibilidade e na visão de curto prazo, emulando valores como lealdade, ajuda mútua e confiança e estimulando outros como a ode ao individualismo e à competitividade, combinados ao gradual desaparecimento de carreiras estáveis e de vínculos profissionais duradouros, indaga-se se tais condições não estariam contribuindo para corrosão do caráter, criando novas subjetividades. A esse cenário, somase a ascensão do ideário neoliberal, onde o mercado aparece como regulador da sociedade, em especial, da relação entre o capital e o trabalho. Ocorre igualmente a abertura dos mercados nacionais como estímulo à concorrência. O Estado de Bem-Estar Social começa ser desestruturado, com a privatização das empresas estatais e o enfraquecimento de suas políticas públicas. Paralelamente, estruturase o Estado mínimo, mas suficientemente forte para conter a inflação, manter a estabilidade monetária, implementar reformas fiscais e abolir controles sobre os fluxos financeiros (Anderson, 1995).

Acredita-se, também, que a considerável progressão, no Brasil, das Lesões por Esforços Repetitivos (LER) ocorre em direta associação com as transformações na organização do trabalho e com a introdução de novas tecnologias que demandam cadências mais rápidas (Merlo, 1997, 1998). Estudos têm mostrado que a incorporação dessas tecnologias - salvo exceções - não reduziram o ritmo de trabalho, mas ocasionaram a sua intensificação, o que está intimamente relacionado com a expansão das LER.

\section{Observações Finais}

Encerrando essas reflexões acerca da interface entre a Psicodinâmica e a Sociologia do Trabalho, é possível evidenciar a estreita relação de saúde com trabalho. Temse presente que as transformações em curso no mundo do trabalho podem ter um efeito positivo sobre os trabalhadores, por meio do uso adequado da tecnologia, no sentido de efetivamente diminuir a carga de trabalho e reduzir a sua jornada, sem decrescer os salários. Mas a alteração do quadro atual depende das relações de força entre os atores envolvidos, empregador e trabalhador, através de seus respectivos sindicatos, intermediados pela participação do Estado, enquanto regulador dessa relação.

Porém, nesses duros tempos sociais, com o enfraquecimento do movimento sindical, a desestruturação do Estado de Bem-Estar Social e de sua rede de proteção de políticas públicas, a desconstituição dos direitos sociais dos trabalhadores, a expansão de formas de trabalho precárias, a elevação das taxas de desemprego e o crescimento da exclusão social, a realidade apresenta-se adversa para importantes segmentos de trabalhadores, afetando sua saúde tanto física como mental (Lapis, 2002).
Quem quer se manter empregado acaba - pela necessidade de formação permanente, a qual implica estar constantemente despendendo energias - tendo a tensão como parte de seu cotidiano. Diante da ameaça da precarização do trabalho e do desemprego, os trabalhadores vivenciam o medo, medo este que reforça, muitas vezes, condutas de obediência, de submissão, quebrando a reciprocidade e a solidariedade entre os colegas de trabalho, na medida em que o temor pessoal separa, individualiza o sofrimento daqueles que estão na mesma condição (Dejours, 2001). Para Dejours, existe o sofrimento dos que exercem tarefas que não foram atingidas pela reestruturação econômica, isto é, taylorizadas, fordizadas. Há também o sofrimento daqueles que têm medo de não serem capazes de manter uma performance adequada no trabalho e de não estarem à altura das novas exigências: de tempo, de cadência, de formação, de informação, de aprendizagem, de nível de conhecimento, de experiência, de adaptação à cultura ou à ideologia da empresa. Assim, às demandas anteriores, típicas do modelo taylorista/fordista, juntam-se agora novos requisitos oriundos da reestruturação promovida pelas firmas para se manterem competitivas.

Pelas novas tendências de organização do trabalho difundidas nas empresas, quem não quer ver seu nome na lista de demissões deve estar sempre pronto a colaborar. A falência ou os avanços da concorrência são referências obrigatórias nas reuniões de equipe, como maneira de conquistar uma dedicação extra, tanto individual quanto coletiva, um esforço maior do trabalhador, intensificando o trabalho para melhorar o desempenho e a qualidade.

Nesse contexto de tendência à precarização das relações de trabalho e de risco constante de ingressar nas estatísticas alarmantes do desemprego, aumentam a ansiedade e o medo do trabalhador, a tal ponto que os desgastes físico e psicológico passam, muitas vezes, a ser banalizados e encarados como se fossem parte da forma normal de trabalhar e viver.

Esse cenário apresenta-se sombrio. Porém a existência, no âmbito internacional, de grupos, classes e movimentos sociais comprometidos com as lutas pela humanização do trabalho e da sociedade pode constituir-se na matriz de um outro padrão civilizatório.

\section{Notas}

1 Taylor e Ford foram contemporâneos, nasceram em 1856e 1863, respectivamente. Parte de suas experiências foram realizadas no mesmo período histórico, pois, enquanto Taylor publicava o livro Princípio de Administração Científica (1911), fruto de seus estudos sobre os tempos e os movimentos, Ford introduzia, em sua fábrica de Highland Park, em 1913, a linha de montagem movida a volante magnético. Neste artigo, o desdobramento analítico dos modelos por eles implentados visa apontar algumas diferenças e semelhanças. Mas a difusão da principal crítica dirigida ao taylorismo é a de que ele impede a conquista da iden- 
tidade no trabalho, a qual ocorre, precisamente, no espaço entre trabalho prescrito e trabalho real. A organização científica do trabalho não se limita apenas à desapropriação do saber; ela inibe também qualquer iniciativa de organização e de adaptação ao trabalho, pois tal adaptação exige uma atividade intelectual e cognitiva não almejada pelo taylorismo (Dejours, 1993), apesar de, na prática, ela não desaparecer totalmente. Os princípios, métodos e técnicas ultrapassaram seus fundadores e solidificaramse em um modelo que, hoje, alguns estudiosos denominam de modelo talylorista-foridsta de organização do trablaho.

2 Chamado também de produção enxuta, produção flexível e automação flexível. Harvey denominou de acumulação flexível as transformações em curso no capitalismo contemporâneo.

3 Embora seja possível apontar distintas tendências, seria um equívoco afirmar-se que o fordismo desapareceu. Existem, sim, variações e caminhos diversos para as empresas, dependendo das características dos países, das regiões e dos setores produtivos. Lipietz (1984) argumenta a respeito da existência de um fordismo periférico, onde tarefas de execução e montagem são transferidas para regiões de salários mais baixos e movimento sindical menos organizado em relação aos dos países do centro, e os produtos da periferia fordista - onde o acesso ao consumo é amplo apenas para segmentos da classe média local mais favorecidos financeiramente e parcial para os operários - são exportados a baixos preços para aqueles países.

\section{Referências}

Anderson, P. (1995). Balanço do neoliberalismo. In E. Sader \& P. Gentili (Eds.), Pós-neoliberalismo: As políticas sociais e o Estado democrático (pp. 09-38). Rio de Janeiro, RJ: Paz e Terra.

Beynon, H. (1995). Trabalhando para Ford: trabalhadores e sindicalistas na indústria automobilística. Rio de Janeiro: Paz e Terra.

Cipolla, F. (2003). Economia Política do Taylorismo, Fordismo e Teamwork. Revista de Economia Política, 23(3), 78-93.

Daniellou, F., Laville, A., \& Teiger, C. (1989). Ficção e realidade do trabalho operário. Revista Brasileira de Saúde Ocupacional, 17 (68), 07-13.

Dejours, C. (1993). A loucura do trabalho. São Paulo, SP: Oboré/ Cortez.

Dejours, C. (2001). A banalização da injustiça (4. ed.). Rio de Janeiro, RJ: Editora da Fundação Getúlio Vargas.

Ferreira, J. M. C. (2002). Novas tecnologias e organização do trabalho. In V. C. Piccinini (Ed.), Caderno de Debates: Vol. 50. Transformações do trabalho e do emprego no contexto da reestruturação econômica. Porto Alegre, RS: Editora da Universidade Federal do Rio Grande do Sul.

Friedmann, G., \& Naville, P. (1962). Traité de sociologie du travail. Paris: Armand Colin.

Gounet, T. (1999). Fordismo e toyotismo na civilização do automóvel. São Paulo, SP: Boitempo.

Gramsci, A. (1978). Americanismo e fordismo. In: A. Gramsci. Obras escolhidas. São Paulo, SP: Martins Fontes.

Harvey, D. (1992). Condição pós-moderna. São Paulo, SP: Loyola.

Heloani, R. (2002). Organização do trabalho: Uma visão multidisciplinar. São Paulo, SP: Cortez.
Lapis, N. L. (2002). Projeto CAPRES/ICCTI n. 093/02, Transformações do trabalho e do emprego no contexto da reestruturação econômica. In: Piccinini, V. (Org.) Caderno de debates. Porto Alegre.

Lipietz, A. (1991). Audácia: Uma alternativa para o século 21. São Paulo, SP: Nobel.

Malaguti, M. L. (1996). A ideologia do modelo japonês de gestão. Ensaios FE, 17(1), 43-73.

Marx, K. (1968). O Capital. Rio de Janeiro, RJ: Civilização Brasileira.

Merlo, A. R. C. (1997). Tecnologia da informação e doenças do trabalho: Um estudo sobre o processamento de massa de dados no Brasil. Saúde Revista do Nipesc, 2, 41-52.

Merlo, A. R. C. (1998). Discursos e sintomas sociais: Uma reflexão sobre as relações de trabalho e saúde. Educação, subjetividade e poder, 5(7), 84-91.

Merlo, A. R. C. (2000). Transformações no mundo do trabalho e saúde. In Associação Psicanalítica de Porto Alegre. O valor simbólico do trabalho e o sujeito contemporâneo (pp. 271-278). Porto Alegre, RS: Artes e Ofícios.

Sennett, R. (2001). A corrosão do caráter: Conseqüências pessoais do trabalho no novo capitalismo. Rio de Janeiro, RJ: Record.

Taylor, F. W. (1995). Princípios de administração científica. São Paulo, SP: Atlas.

Teiger, C. (1980). Les empreintes du travail. In Sociétè Française de Psychologie. Equilibre et fatigue par le travail (pp. 25-44). Paris: Entreprise Moderne.

Álvaro Roberto Crespo Merlo é médico e doutor em Sociologia. Docente da Faculdade de Medicina, do Programa de Pós-Graduação em Psicologia Social e Institucional e do Programa de Pós-Graduação em Epidemiologia da Universidade Federal do Rio Grande do Sul - UFRGS. Endereço para correspondência: UFRGS (Medicina Social) - Rua Ramiro Barcellos, 2600 (4 ${ }^{\circ}$ andar) - CEP 90035-003 - Porto Alegre, RS.

merlo@ufrgs.br

Naira Lima Lapis é socióloga e doutora em Sociologia. Docente do Departamento de Sociologia e do Programa de Pós-Graduação em Sociologia da UFRGS. nairalima@cpovo.net

\section{A saúde e os processos de trabalho no capitalismo contemporâneo: reflexões na interface da Sociologia do Trabalho e da Psicodinâmica do Trabalho}

Álvaro Roberto Crespo Merlo e Naira Lima Lápis

Recebido: 27/04/2006

$1^{\text {a } \text { revisão: } 27 / 08 / 2006}$

Aceite final: 20/10/2006 